O. M. Velychko, DSc, L. V. Kolomiets, DSc, T. B. Gordiyenko, PhD

\title{
A CHOICE OF METHODS OF GENERAL EVALUATION OF RISKS IN THE FIELD OF TECHNICAL REGULATION
}

In international standards various methods are standardized for general evaluation and management risks that apply for a management, control and improvement of processes. The comparative analysis of the standardized methods of general evaluation of risks is conducted and offered recommendation for its using. Some features of application of methods of general evaluation risks are considered.

Keywords: method of evaluation of risks, common evaluation of risks, technical regulation, standard.

\section{УДК 657.6}

\author{
Л. В. Коломиец ${ }^{1}$, д.т.н., А. И. Новикова ${ }^{1}$, Р. В. Злобин ${ }^{2}$, В. И. Новиков ${ }^{2}$ \\ ${ }^{1}$ Одесская государственная академия технического регулирования и качества, г. Одесса \\ ${ }^{2}$ Государственное предприятие «Одесский региональный чентр стандартизачии, метрологии $и$ \\ сертификаиии», г. Одесса
}

\section{НЕКОТОРЫЕ АСПЕКТЫ МЕТРОЛОГИЧЕСКОГО ОБЕСПЕЧЕНИЯ УЧЕТА ПИЩЕВОЙ И ЛИКЕРО-ВОДОЧНОЙ ПРОДУКЦИИ}

В данной статье обосновывается необходимость внесения изменений в существуюшую нормативную документачию (НД), решение проблем учета в отрасли вино-водочного производства и рассматриваются функииональные возможности, которые будут способствовать повышению достоверности измерений и качества продукции.

Ключевые слова: учет, контроль, технические требования, техническая документачия, методики поверки.

Учет и контроль - основа успешной деятельности любого предприятия, организации, государства - в конечном итоге.

Оглядываясь на сокращающиеся запасы природных и сырьевых ресурсов, становится всё очевидней актуальность их учета и контроля, особенно на предприятиях, перерабатывающих сельскохозяйственную продукцию.

Рассмотрим вопросы учета в винодельческой, спиртовой, консервной промышленности и проблемы, возникающие при определении количества тех или иных продуктов.

С давних пор так сложилось, что виноводочное производство приносит большую долю поступлений в бюджет страны и поэтому каждый недоучтенный литр (дм $\left.{ }^{3}\right)$ данной продукции оборачивается значительными недопоступлениями в казну государства.

Поэтому так важно точно знать: 1) где? 2) чего? 3) сколько? в каждый момент времени.

И если в отношении виноматериалов вопрос качества учета стоит не так остро, то, что касается спирта и его производных, есть необходимость совершенствования процесса этого учета в плане повышения достоверности результатов.
На отечественных предприятиях ликероводочной промышленности используется огромный парк различных типов мерников, емкостей (реакторов, купажеров, трубопроводов) и другого технологического оборудования.

Возникает резонный вопрос: «А сколько в том или ином объеме в данный момент находится продукта?», то есть существует необходимость создания градуировочных таблиц, составленных с погрешностью, приемлемой для объективного, достоверного учета.

Известно, что такие таблицы могут составляться как на основе геометрического метода определения объема, так и на основе метода налива с применением эталонных средств измерительной техники (СИТ).

Не будем останавливаться на перечислении тех СИТ, которые используются при поверке или калибровке тех или иных пищевых емкостей, а остановимся на вопросах, возникших на сегодняшний день и не имеющих ответов в НД.

В настоящее время в Одесском регионе явно просматривается возрождение виноделия - восстанавливаются старые заводы и строятся новые. За короткий срок восстановлены заводы в горо- 
дах: Белгород-Днестровский, Болград, Измаил, Килия и других.

Для приготовления, хранения, переработки, купажирования и розлива вина и виноматериалов винзаводы должны быть оснащены резервуарным парком. Вино и виноматериалы длительное время должны храниться в этих резервуарах и, учитывая, что вино и виноматериалы в настоящее время не дешевы (примерно 1 евро за литр, что сопоставимо с ценами на нефтепродукты), то они могут быть приравнены к стратегическому сырью.

У предприятий виноделия возникает потребность в правильном и достоверном учете вина и виноматериалов, кроме того достоверный учет виноматериалов на предприятиях позволяет свести до минимума технологические и непроизводственные потери.

Так как отдельные винзаводы производят и продают только виноматериалы, то эти резервуары входят в сферу государственного метрологического надзора (ГМН) и должны проходить процедуру поверки или государственной метрологической аттестации (ГМА).

По технологии производства вина из резервуаров должны отбираться пробы на лабораторный анализ.

Однако в настоящее время отсутствует НД на общие технические требования к резервуарам для вина, виноматериалов и других пищевых продуктов, а также методики их поверки.

Для удобства пользования и проведения учетных, учётно-расчетных операций с вином, виноматериалами и другими пищевыми продуктами конструкцию резервуаров необходимо доработать, установив дополнительные водомерные трубки и шкалы. Затем отградуировать их объемным или геометрическим методом и провести поверку.

Кроме того, желательна установка водомерных трубок с трехходовыми краниками для удобства отбора проб.

Дважды в год на винзаводах совместно с налоговыми органами, проводится инвентаризация спирта, вина и виноматериалов, поэтому наличие градировочных таблиц на резервуары для вина и виноматериалов позволит вести их достоверный учет.

В 1987 году Госагропромом Украины предприятиям перерабатывающих отраслей было направлено письмо № 18 - 1 - ХР / 18 о сроках и правилах градуировки емкостей, где были установлены порядок проведения и сроки градуировки резервуаров (1 раз в 2 - 5 лет в зависимости от сроков эксплуатации).
Проведение метрологических работ по градуировке и поверке резервуаров для вина и виноматериалов позволит предприятиям регулярно контролировать состояние резервуарного парка, вести достоверный учет, сократить потери, что в конечном итоге должно отразиться на качестве выпускаемой продукции.

Отдельно стоит вопрос о транспортных меpax для пищевых жидкостей. Основное в этом вопросе то, с какой точностью необходимо определять их вместимость: 0,2 \% или 0,5\%. Тарифы на поверку что одних, что других транспортных мер одинаковы, а если определять вместимость транспортной меры с точностью $0,2 \%$, то затраты по времени гораздо больше. Учитывая, что цена на виноматериалы сопоставима с ценой на нефтепродукты, предлагается определять их вместимость с точностью $0,5 \%$, а вместимость транспортных мер для перевозки спирта определять с точностью $0,2 \%$, но при этом увеличить тариф на их поверку. В 1989 году Одесским научно-производственным объединением «Пищепромавтоматика», трестом «Огрпищепром», ремонтно-механическим комбинатом «Киевреммашналадка» и экспериментальным управлением «Антипор» разработаны «Методические указания РД 10-04-5-87 [1]. Резервуары и технологическое оборудование стандартные и измерительные. Определение общей и интервальных вместимостей», которые были согласованы с ВНИИ расходометрии Госстандарта СССР и утверждены Госагропромом СССР.

Градуировка резервуаров проводится с целью использования их как рабочих СИТ измерения объемов жидких пищевых продуктов для учета, взаимных расчетов, а также для измерения и контроля количества продуктов при дозировании, хранении и других технологических операциях.

В методике приведен порядок определения вместимости резервуаров для пищевых продуктов геометрическим и объемным методами, применяемые для этих целей СИТ и необходимое оборудование, а также порядок составления градуировочных таблиц.

Следует отметить, что эта методика устарела и нуждается в переработке.

Рассмотрим некоторые особенности этого нормативного документа. Величины допускаемой относительной погрешности находятся в пределах:

- определения общей вместимости резервуаров и технологического оборудования геометрическим и объемным методом - $\pm 0,4 \%$;

- определения интервальных вместимостей резервуаров и технологического оборудования - 
$\pm 0,6 \%$.

В соответствии с п. 1.6 методики, резервуар может быть аттестован в качестве измерительного при условии соответствия и наличия необходимых СИТ и документов по результатам градуировки резервуара. Таким образом, существует необходимость ввести в методику определение «Измерительный резервуар», а также связанные с ним поняти. При этом допускаемые погрешности измерений в соответствии с методикой существенные (по ДСТУ 4147 [2] - 0,1\%, по ДСТУ 4218 [3] - 0,25\%).

Кроме того, к недостаткам методики можно отнести то, что не приведены возможные формы резервуаров, отсутствуют требования к водомерным трубкам, внутренним покрытиям, устаревшее программное обеспечение (ПО) для составления градуировочных таблиц и другие.

\section{Вывод}

На предприятиях перерабатывающей промышленности, имеющих установленные резервуары для хранения, переработки и реализации сырья, полуфабрикатов и готовой продукции необходимо:

1. Запретить их использование без предварительного определения компетентными организациями их действительной вместимости и градуировки с определением погрешности резервуаров, с составлением и утверждением в установленном порядке градуировочных таблиц.

2. Разработать необходимую техническую документацию, устанавливающую технические требования к пищевым резервуарам, методику их поверки и ПО для расчета таблиц по результатам поверки.

3. При разработке методики поверки и ПО для расчета градуировочных таблиц предусмотреть градуировку резервуаров геометрическим методом по недоливу для удобства пользователей и ввиду особенностей конструкций этих резервуаров.

4. Разработать правила эксплуатации резервуаров (сроки и порядок проведения зачистки, требования к уплотняющим материалам, водомерным трубкам, шкалам, пломбированию и т.д.)

5. Возложить ответственность за комплектность и исправное состояние СИТ и резервуарного парка на руководителей предприятий, которые, в свою очередь, должны назначить ответственных лиц.

\section{Список использованных источников}

1.«Методические указания РД $10-04-5-$ 87. Резервуары и технологическое оборудование стандартные и измерительные. Определение общей и интервальных вместимостей».

2. ДСТУ 4218:2003 Метрологія. Резервуари стальні горизонтальні циліндричні. Методика повірки (ГОСТ 8.346 - 2000, MOD).

3. ДСТУ 4147:2003 Метрологія. Резервуари сталеві вертикальні циліндричні. Методика повірки (ГОСТ $8.570-2000$, MOD).

Поступила в редакиию 22.11.2013

\title{
Л. В. Коломісць, Д.т.н., А. І. Новікова, Р. В. Злобін, В. І. Новіков
}

\section{ДЕЯКІ АСПЕКТИ МЕТРОЛОГІЧНОГО ЗАБЕЗПЕЧЕННЯ ОБЛІКУ ХАРЧОВОЇ І ЛІКЕРО - ГОРІЛЧАНОї ПРОДУКЦІї}

В даній статті обгрунтовується необхідність внесення змін у існуючу нормативну документаиію, вирішення проблем обліку в галузі вино-горілчаного виробництва та розглядаються функиіональні можливості, що сприятимуть підвищенню достовірності вимірювань і якості продукиії.

Ключові слова: облік, контроль, технічні вимоги, технічна документаиія, методики перевірки.

\author{
L.V. Kolomiets, DSc, A. I. Novikova, R. V. Zlobin, V. I. Novikov
}

\section{SOME ASPECTS OF METROLOGY ASSURANCE ACCOUNT FOOD AND LIQUEUR AND TO VODKA PRODUCTS}

In this article the necessity of making alteration is grounded for existent normative documentation, decision of problems of account in industry wine - vodka production and functional possibilities that will assist the increase of authenticity of measuring and quality of products are examined.

Keywords: account, control, technical requirements, technical documentation, methodologies of check. 